\title{
Uso e aplicações medicinais da mamorana (Pachira aquatica Aublet) pelos ribeirinhos de São Lourenço, Igarapé-Miri, estado do Pará, Amazônia
}

\author{
Use and medicinal applications of mamorana (Pachira aquatica Aublet) by the \\ ribeirinhos (river dwellers) of São Lourenço, Igarapé-Miri, state of Pará, Amazon
Uso y aplicaciones medicinales de mamorana (Pachira aquatica Aublet) por los ribereños de São Lourenço, Igarapé-Miri, estado del Pará, Amazonia

\author{
Gracilene Ferreira Pantoja ${ }^{1}$ \\ Yvens Ely Martins Cordeiro ${ }^{1}$ \\ Sebastião Gomes Silva ${ }^{1}$ \\ Ronaldo Lopes de Sousa ${ }^{1}$
}

Recebido em 07/09/2018; revisado e aprovado em 29/04/2019; aceito em 22/05/2019

DOI: http://dx.doi.org/10.20435/inter.v21i3.2146

\begin{abstract}
Resumo: A pesquisa objetivou fazer um levantamento sobre o uso e as aplicações medicinais da mamorana (Pachira aquatica Aublet) pelos ribeirinhos do Baixo Rio São Lourenço, Distrito de Maiauatá, município de Igarapé-Miri, estado do Pará. O público-alvo da pesquisa compreende onze (11) ribeirinhos que têm maior idade em seu núcleo familiar, sendo de famílias diferentes, tendo históricos do uso de plantas. Foram registrados nove (9) tipos diferentes de indicações e/ou usos da Pachira aquatica Aublet, a qual é utilizada para dor de ouvido, tratamento de colesterol, diabetes, escabiose ("curuba"), inflamação e hematoma nos olhos, "carne crescida" nos olhos e conjuntivite, além de ser usada para tingir redes de lancear.
\end{abstract}

Palavras-chave: mamorana, planta medicinal; ribeirinhos; Baixo Tocantins; Amazônia.

Abstract: The objective of the research was to survey the use and medicinal applications of mamorana (Pachira aquatica Aublet) by the ribeirinhos (river dwellers) of Baixo Rio São Lourenço, Maiauatá District, Igarapé-Miri municipality, state of Pará. The target audience of the research comprises eleven (11) ribeirinhos who are older in their family nucleus, being from different families, with histories of the use of plants. We recorded nine (9) different types of indications and/or uses of Pachira aquatica Aublet, which is used for ear pain, cholesterol treatment, diabetes, scabies ("curuba"), inflammation and hematoma in the eyes, "overgrown meat" in the eyes, and conjunctivitis, in addition to being used to dye artisanal fishing nets.

Keywords: mamorana, medicinal plant; ribeirinhos; Lower Tocantins; Amazon.

Resumen: La investigación objetivó hacer un levantamiento sobre el uso y las aplicaciones medicinales de la mamorana (Pachira aquatica Aublet) por los ribereños de Bajo Rio São Lourenço, Distrito de Maiauatá, municipio de Igarapé-Miri, estado del Pará. El público objetivo de la investigación comprende once (11) ribereños que tienen mayor edad en su núcleo familiar, siendo de familias diferentes, teniendo históricos del uso de plantas. Se registraron nueve (9) tipos diferentes de indicaciones y/o usos de la Pachira aquatica Aublet, la cual es utilizada para dolor de oído, tratamiento de colesterol, diabetes, escabiosis ("curuba"), inflamación y hematoma en los ojos, "carne crecida" en los ojos y conjuntivitis, además de ser usada para teñir redes de pesca artesanal.

Palabras clave: mamorana, planta medicinal; ribereños; Bajo Tocantins; Amazonia.

\section{INTRODUÇÃO}

Na Amazônia, é comum o uso de plantas medicinais no tratamento de muitas doenças, especialmente pelos povos tradicionais ${ }^{2}$, os quais detêm um conjunto de práticas, valores, crenças

\footnotetext{
${ }^{1}$ Universidade Federal do Pará (UFPA), Campus Abaetetuba, Pará, Brasil.

${ }^{2}$ Art. 30 "São grupos culturalmente diferenciados, que se reconhecem como tais, que possuem formas próprias de organização social, que ocupam e usam territórios e recursos naturais como condição para a sua reprodução cultural, social, religiosa, ancestral e econômica, utilizando conhecimentos, inovações e práticas gerados e transmitidos pela tradição" (BRASIL, 2007).
} 
e concepções simbólicas que, ao longo do tempo, ressignificam e perpetuam entre as gerações. De acordo com Bôas (2016), esse saber no que diz respeito à terapêutica natural, por meio do uso de ervas medicinais, é praticado pelos ribeirinhos.

Santos-Silva e Oliveira (2016, p. 137) afirmam que:

[...] Os ribeirinhos possuem grande valor cultural, por conta de sua estreita relação com o meio em que vivem, sendo que este é um ambiente bastante versátil, e que exige que os organismos que se estabelecem nele sejam versáteis também. Por esse motivo, as várzeas e as populações que nela habitam tornam-se cada vez mais alvos de pesquisas, onde procurase entender principalmente a relação homem/natureza nesse ecossistema.

Essas formas/maneiras que os ribeirinhos têm de se inter-relacionar com o seu meio ambiente constituem modos particular de vida, os quais estão intimamente voltados ao uso do território e de suas diversas formas de uso e manejo dos recursos naturais, a exemplo do uso de plantas medicinais, uma das práticas terapêuticas muito comuns nas várzeas, sobretudo no município de Igarapé-Miri, como afirma Pinto (2008).

No entanto é importante frisar que a continuidade dessas práticas pode ser ameaçada por ações antrópicas, como mudanças no ambiente natural em que esses povos vivem, além de pressões econômicas e culturais externas. Couto-Waltrich et al. (2017) afirmam que a degradação dos ecossistemas naturais vem ameaçando muitas espécies, necessitando de ações para sua conservação, devido ao grande valor tradicional de uso pelos povos.

Diante disso, reporta-se às comunidades ribeirinhas do Baixo Tocantins, em especial as do município de Igarapé-Miri, PA, em que a prática do uso de plantas medicinais encontra-se ameaçada, de certa forma, visto que, nas últimas décadas, as comunidades vêm passando por diversas transformações socioambientais, como a degradação dos recursos naturais, mudanças no modo de vida das pessoas, o qual tem se assemelhado ao citadino, e até mesmo no âmbito da agricultura, conforme enfatiza Pantoja et al. (2018), o que vem alterando a paisagem local.

De acordo com Elisabetsky (2003), a perda da biodiversidade e o acelerado processo de mudança cultural que vem ocorrendo acrescentam um senso de urgência no registro e na valoração desse saber, sobretudo em relação às plantas de uso medicinal que os sujeitos ainda cultivam e utilizam.

Neste estudo, destaca-se a árvore de mamorana (Pachira aquatica Aublet), que muito já foi utilizada para fins terapêuticos pelos ribeirinhos do São Lourenço, no município de IgarapéMiri, Pará, e da qual há, hoje, poucas evidências de uso. Daí surgiu a necessidade de investigação junto aos sujeitos deste lócus de pesquisa, para saber se esses ainda a utilizavam e como estava a distribuição desse conhecimento por diferentes famílias desse lugar.

\subsection{Mamorana (Pachira aquatica Aublet)}

A Pachira aquatica Aubl. é uma planta nativa do sul do México até o norte da América do Sul, sendo comumente encontrada nas margens das áreas de várzea e/ou terrenos alagados. Suas características permitem que seja considerada como uma espécie de maré alta (INFANTE-MATA; MORENO-CASASOLA; MADERO-VEGA, 2014). De acordo com Cheng et al. (2017), ela é introduzida em Guangdong, no sul de Yunnan e em Taiwan como planta cultivada e comercialmente vendida sob a denominação de árvore de dinheiro e planta de dinheiro, sendo uma planta de casa comum. É muitas vezes referida como uma árvore de dinheiro, já que ela supostamente traz boa sorte e dinheiro para a casa do proprietário. 
No Brasil, ela tem inúmeros termos que são sinônimos, como munguba, castanhola, cacauselvagem, castanha-do-maranhão, entre outras variações, que têm origem do termo ibonguiaba, ibomguiva, visto que, no período de colonização do Brasil, muitos termos de origem indígena eram incorporados ao idioma português, sobretudo a partir de interpretações sonoras por missionários, viajantes e naturalistas ao longo do tempo, daí a grande variação linguística da planta (PEIXOTO; ESCUDEIRO, 2002).

A Pachira aquatica faz parte da composição da mata ciliar em áreas de várzea, em que, em alguns casos, é implementada até mesmo na recuperação de áreas degradadas. Estudos apontam que ela é utilizada para arborização de centros urbanos, devido a sua fácil adaptação climática (LORENZI, 1992) - um fator de extrema relevância a ser considerado em relação às questões ambientais atuais.

\subsubsection{Classificação botânica e fisiológica}

A Pachira aquatica Aubl. (Figura 1A) é árvore pertencente ao grupo das angiospermas, família Malvaceae (INFANTE-MATA; MORENO-CASASOLA; MADERO-VEGA, 2014), ordem Malvales, "possui aproximadamente 20 metros de altura, com folha palmada, 5-9-foliolada, folíolos oblanceolados a obovado-oblongos, $5-21 \mathrm{~cm}$ de comprimento e $1.5-8 \mathrm{~cm}$ de largura, ápice abruptamente acuminado a arredondado, base cuneada" (PESCE, 2009, p. 276).

Tem flores solitárias, de cor amarela na base e tons avermelhados na extremidade (Figura 1B). Estas têm aroma adocicado que atrai vários insetos: mariposas, besouros, abelhas, formigas e morcegos (PEIXOTO; ESCUDEIRO, 2002). "Florescem principalmente durante os meses de setembro a novembro" (SILVA; LEMOS, 2002, p. 113).

O fruto é oblongo a ovoide, com superfície aveludada e áspera de cor marrom, (Figura 1C), medindo entre 15 e $20 \mathrm{~cm}$ de comprimento por 12 a $14 \mathrm{~cm}$ de diâmetro, contendo válvulas lenhosas e sulcos longitudinais nas junções dos diversos setores que a compõem (PESCE, 2009, p. 276). Os frutos amadurecem predominantemente em abril a junho (SILVA; LEMOS, 2002, p. 113).

As sementes que se encontram no fruto são irregulares, desnudas, na cor do fruto, geralmente em número de 40, mais ou menos aconchegadas, mas completamente separadas por meio de uma membrana pouco consistente (Figura 1D) (PESCE, 2009, p. 276). 
Figura 1 - A) planta da mamorana (Pachira aquatica Aubl.); B) Flor da mamorana (Pachira aquatica Aubl.); C) Fruto mamorana (Pachira aquatica Aubl.); D) Semente mamorana (Pachira aquatica Aubl.).

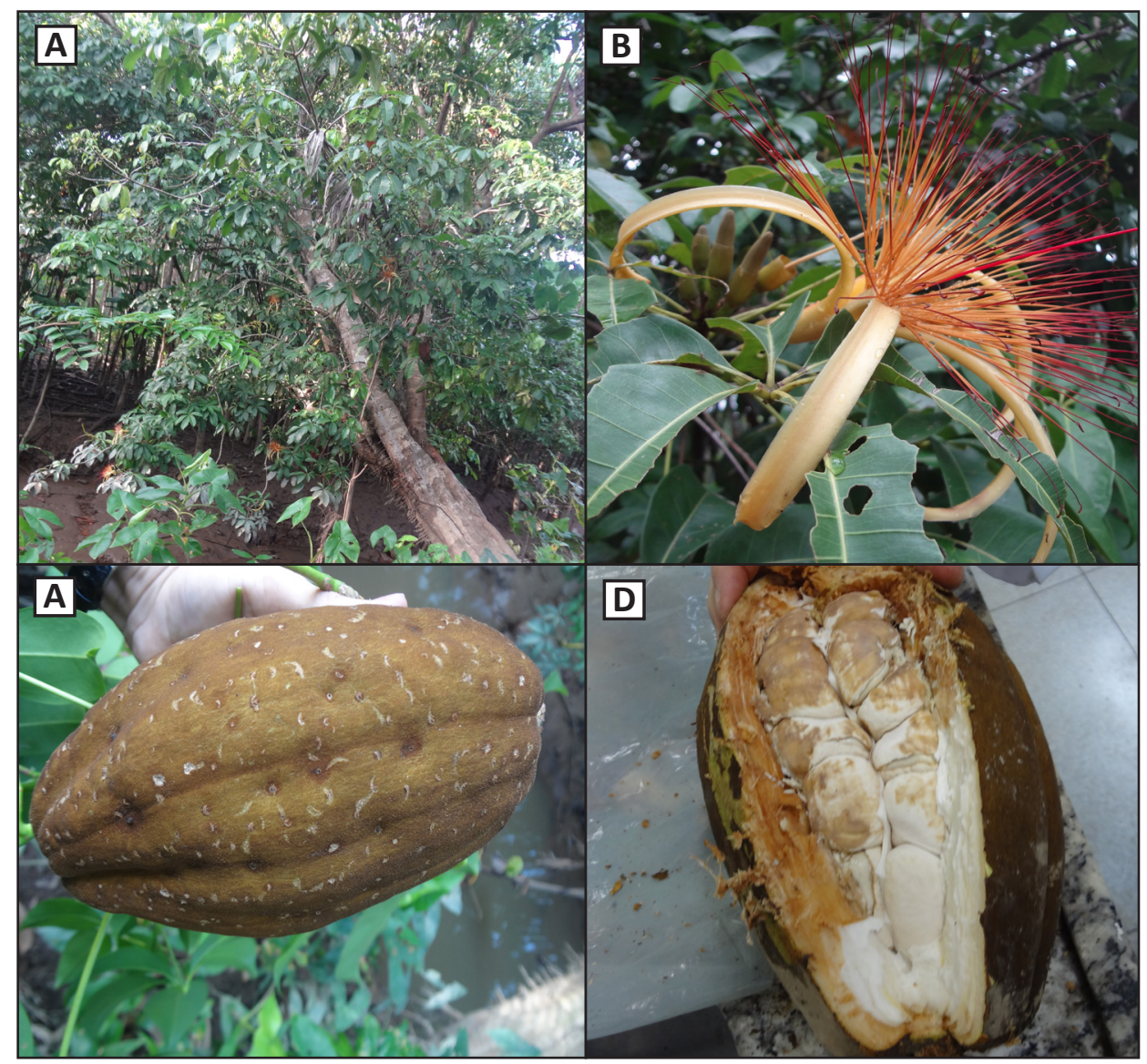

Fonte: Pesquisa de campo, 2018.

\subsection{Plantas medicinais: conceito e histórico}

Definem-se as plantas medicinais como "recursos naturais com propriedades capazes de provocar reações benéficas no organismo, utilizadas na recuperação e manutenção do bemestar" (SILVA, 2018, p. 7).

Segundo Jorge (2009), as plantas medicinais têm substâncias químicas (princípios ativos) ${ }^{3} \mathrm{com}$ ação farmacológica, podendo ser utilizadas para prevenir, tratar ou curar determinada doença, sendo que os princípios ativos servem para atuar em benefício da planta, sobretudo na proteção e/ou defesa ao ataque de pragas, doenças e atração de polinizadores.

O uso de plantas medicinais é uma tradição muito antiga, sendo também uma prática de diversas civilizações. De acordo com Jorge (2009); Almeida (2011); Braga (2011) e Abílio (2011) há 3000 a. C., na China, as plantas já eram utilizadas com finalidades terapêuticas. O imperador Cheng-Nung tinha o hábito de usar plantas em seu próprio corpo com o propósito de constatar a eficácia e o efeito que provocavam. Entre 252 plantas, das quais resultou um "cânone das ervas", destacou a raiz de ginseng, considerando-a uma das mais fabulosas ervas, a

\footnotetext{
3 "São compostos químicos secundários sintetizados pelas plantas através dos nutrientes, da água e da luz que a planta recebe" (JORGE, 2009, p. 16).
} 
qual, segundo ele, favorecia a longevidade. Conta a história de que o imperador viveu 123 anos. Jorge (2009) e Abílio (2011) enfatizam que a erva ginseng é muito utilizada nos dias atuais, principalmente na regeneração dos tecidos e melhoria do funcionamento de algumas glândulas, além de estimular a atividade cerebral, proporcionando o rendimento mental, sendo também uma alternativa de tratamento para várias doenças do coração, dos rins, do sistema nervoso e circulatório, entre outras.

É importante ressaltar que, assim como a cultura chinesa tinha o conhecimento sobre plantas medicinais e as manipulava, aproveitando de seus benefícios, os assírios, egípcios e índios também cultivavam e utilizavam plantas para inúmeras finalidades. Inclusive, o conhecimento sobre muitas delas era resultado de várias expedições que eles realizavam em diversos territórios.

No que diz respeito à medicina egípcia, por exemplo, Abílio (2011) afirma que esta se apoiava em elementos mágicos e religiosos. Jorge (2009) reitera que, por esse motivo, as plantas eram escolhidas pelo seu cheiro, pois esses povos acreditavam que determinados aromas afugentavam os espíritos das enfermidades. Os curandeiros, por exemplo, utilizam muito as plantas em seus preparos mágicos. O primeiro deles a fazer esses usos foi o médico egípcio Imhotep (2980 a 2900 a. C.).

Além do uso terapêutico, Braga (2011) ressalta que os egípcios utilizavam também uma grande variedade de plantas na preparação de múmias, cujo conhecimento a respeito ainda não foi desvendado totalmente.

É necessário destacar que muitos conhecimentos em torno das ervas foram sendo documentados ao longo dos séculos. Jorge (2009) e Almeida (2011) destacam, como referência, o "Papiro de Ebers", um dos herbários mais antigos (1550 a. C.), contendo 125 plantas e 811 receitas.

Embora sejam inúmeras as contribuições das civilizações anteriores, os gregos foram os primeiros a sistematizar o conhecimento sobre as ervas. De acordo com Braga (2011), no ano de 400 a. C., Diocles escreveu seu primeiro livro sistematizando o conhecimento adquirido até aquele momento, entre tantos outros, como Hipócrates, Pelácios e Plínio Velho. Segundo Abílio (2011), o conhecimento grego sobre ervas foi adquirido na Índia, na Babilônia, no Egito e até na China.

Porém é preciso ressalvar que, com o fortalecimento da Igreja Católica na Idade Média, muitas pesquisas foram estagnadas pelo fato de a igreja ser contrária ao desenvolvimento dos conhecimentos científicos. Somente no século XIII, quando surgem as escolas de Salermo e Montpellier, que o assunto sobre as plantas é retomado. E, no ano de 1484, foi impresso o primeiro livro sobre as plantas medicinais, o qual se utilizou dos escritos de Dioscórides (BRAGA, 2011; JORGE, 2009).

\subsection{Uso de plantas medicinais no Brasil}

As plantas medicinais no Brasil eram utilizadas desde os primeiros habitantes que aqui viviam; eles usavam as plantas não só para finalidades terapêuticas, mas também para suprir outras necessidades. Historicamente, quando os colonizadores europeus chegaram ao nosso país, perceberam a forte relação que os povos indígenas estabeleciam com a natureza. Encontraram índios que usavam urucum para pintar e proteger o corpo das picadas de insetos e também para tingir seus objetos cerâmicos (ABÍLIO, 2011).

Posteriormente, com a escravidão no Brasil, outro povo que contribuiu significativamente com essa cultura foram os africanos. De acordo com Almeida (2011, p. 44), "os levantamentos etnomédicos realizados demonstram a forte influência da herança cultural africana na medicina popular do Brasil, principalmente no norte, nordeste e sudeste do país". 
A autora afirma ainda que, após três séculos de tráfico escravo, muitas foram as espécies trazidas, outras também levadas daqui para o continente africano, ou seja, era realizado um duplo trabalho pelos negros.

Com essa prática de inserir plantas nativas do Brasil em sua cultura, outras práticas originárias da África iam perdendo seu significado simbólico, sobretudo algumas que eram utilizadas em rituais. Dessa forma, a cultura europeia ia se disseminando no país e afastando as crenças e práticas de seus antepassados, principalmente após a abolição, com o chamado refluxo migratório dos africanos e de seus descendentes (ALMEIDA, 2011).

Ao mesmo tempo, esse evento ocorria aqui no Brasil, pois muitos espécimes foram incorporados à nossa cultura, a exemplo do dendê, mamona, quiabo, entre outros, que inclusive se adaptaram muito bem, como enfatiza Almeida (2011).

Esse processo levou muitos conhecimentos e práticas a se perderem. No Brasil, por exemplo, o conhecimento dos índios, africanos e seus descendentes está desaparecendo, devido à imposição de hábitos culturais oriundos de outros países; paralelamente a isso, há uma invisibilização desses e dos demais povos tradicionais, no geral, que hoje exercem territorialidades específicas e se autodenominam (ribeirinhos, quilombolas, caiçaras, entre outros), mas veem suas práticas, seus saberes e modos de vida sendo ameaçados, havendo um iminente risco de desaparecer essa importante memória cultural.

Nesse sentido, a academia assume um papel primordial, no sentido de dar voz a esse conhecimento que é de suma importância para as comunidades, não somente para preservar seus saberes, mas também, como enfatiza Silva et al. (2011), de compreendê-los, no sentido de propor e executar projetos voltados para a área da saúde pública adaptados à realidade sociocultural e econômica, sobretudo onde a prática desse conhecimento ainda se faz presente, e, dessa forma, construir pontes entre o saber popular e o saber científico, possibilitando a produção do conhecimento e sua prática adequada em cada comunidade.

Desse modo, objetivou-se fazer um levantamento sobre o uso e as aplicações medicinais da mamorana (Pachira aquatica Aublet) no Rio São Lourenço, Distrito de Maiauatá, município de Igarapé-Miri, estado do Pará.

\section{METODOLOGIA}

A seguir, relata-se de que maneira foi realizada esta pesquisa, o lócus de estudo e públicoalvo, além da forma como os dados foram coletados e analisados para que fosse possível atingir os objetivos propostos.

\subsection{Lócus de estudo e público-alvo}

A pesquisa foi realizada no Rio São Lourenço - em uma das ilhas fluviais pertencentes ao município de Igarapé-Miri, PA, banhada pelo Rio Tocantins -, distrito de Maiauatá, estando este situado a, aproximadamente, uma hora e trinta minutos (1h30min) de barco até a sede do município.

O público-alvo da pesquisa corresponde a onze (11) ribeirinhos, sendo adotados os seguintes critérios para a seleção desses: 1) maior idade/longevidade; 2) um único ribeirinho por cada família; 3) apenas os quais residem no Baixo Rio São Lourenço, onde há um histórico do uso das plantas medicinais; e 4) aceitar o convite para contribuir na pesquisa, assinando um 
Termo de Consentimento Livre e Esclarecido, seguindo normas éticas destinadas a pesquisas feitas com seres humanos, de acordo com regras do Item IV da Resolução n. 466, de 12 de Dezembro de 2012.

\subsection{Coleta e identificação do espécime}

Para realizar a herborização e identificação taxonômica da planta citada, foram coletados, no mês de Março de 2018, três (3) ramos com folhas e flores às margens de um igarapé do lócus de pesquisa (Figura 2), os quais foram armazenados em um saco plástico umedecido por dentro e levados até o Instituto Federal do Pará (IFPA), Campus Abaetetuba, onde foram prensados, secos ${ }^{4}$ e incorporados ao herbário ${ }^{5}$.

No momento da coleta e do deslocamento até os informantes, foram feitas tomadas de Sistema de Posicionamento Global (GPS), com auxílio do aplicativo Android "GPS Essentials" (disponível em: https://play.google.com/store/apps/details?id=com.mictale.gpsessentials\&hl=pt_ $\mathrm{BR}$ ); com isso, construiu-se um mapa do ponto de coleta da planta, contendo o lócus de pesquisa, utilizando-se do programa ArcGis. ${ }^{6}$

Figura 2 - Material botânico coletado

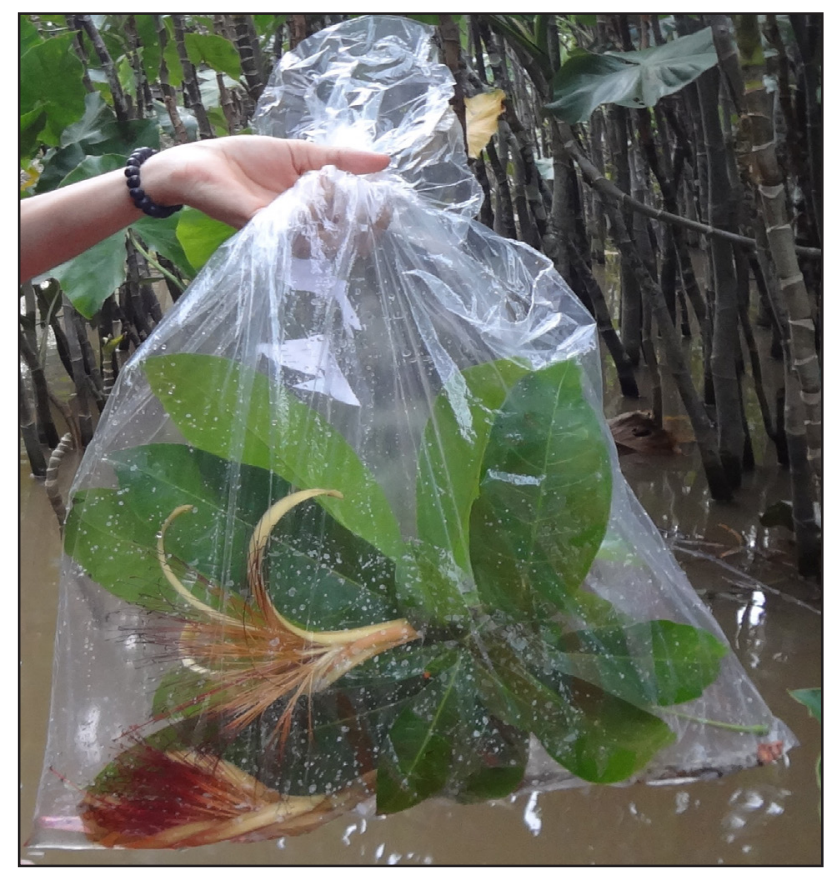

Fonte: Pesquisa de campo, 2018.

\footnotetext{
${ }^{4}$ A secagem tem por objetivo retirar a água existente no interior da planta (desidratar) para conservá-la por mais tempo (ALMEIDA, 2011, p. 151).

5 "São instituições, geralmente associadas a institutos de pesquisa ou universidades, que abrigam coleções de materiais botânicos, secos, identificados e ordenados, destinados à exposição e ao estudo" (JORJE, 2009, p. 14).

6 "É um dos softwares de Sistema de Informações Geográficas - SIG, amplamente utilizado por profissionais na área de geoprocessamento por possuir uma interface completa que permite a inserção, visualização e manipulação de dados geográficos relacionais e ainda uma impressão final de qualidade profissional" (SEBEM; MONGUILHOTT, 2010, p. 5).
} 


\subsection{Coleta de dados com os ribeirinhos}

Para o levantamento de dados junto aos ribeirinhos do Baixo Rio São Lourenço, realizaramse entrevistas no mês de março de 2018, tendo como auxílio um roteiro com oito (8) questões norteadoras sobre a temática, um diário de campo para registros de informações e um gravador de voz (com autorização do entrevistado). A partir dessas entrevistas, foram obtidas informações a respeito do perfil pessoal dos informantes (idade, sexo, nível de escolaridade, profissão e origem) e sobre a planta (uso, parte utilizada, modo de preparo, indicações, dosagem e herança do conhecimento a respeito dela).

\subsection{Tratamento e análise dos dados}

As narrativas obtidas neste estudo foram transcritas e analisadas de forma quantitativa e qualitativa, sendo mantida com autenticidade a linguagem dos entrevistados. No momento da análise, optou-se pela não identificação por nomes dos sujeitos, de forma a preservar suas identidades.

\section{RESULTADOS E DISCUSSÕES}

A seguir, são apresentados os resultados da pesquisa e discutidos a partir das experiências em campo e diálogo com os autores que deram embasamento teórico nas análises.

\subsection{Localização da área de coleta/lócus de pesquisa}

O município de Igarapé-Miri (Figura 3) pertence à Mesorregião do Nordeste Paraense e está localizado na margem direita do rio homônimo, na zona fisiográfica Guajarina, região de integração do Baixo-Tocantins. Limita-se ao Norte com o município de Abaetetuba; a Leste, com o município de Moju; ao Sul, com o município de Cametá e Moju; e a Oeste, com os municípios de Cametá e Limoeiro do Ajuru.

Uma das ilhas fluviais deste município é o Rio São Lourenço, onde foi realizada a coleta do vegetal estudado, o qual se encontra na coleção botânica do herbário do Instituto Federal do Pará (Hifpa) (Figuras 4, A e B). A ilha citada tem mata de várzea baixa, estando localizada a uma latitude 01은 52.719’ Sul e a uma longitude 04906.135’ Oeste, com altitude de 20 metros. 
Figura 3 - Mapa de coleta e lócus de pesquisa
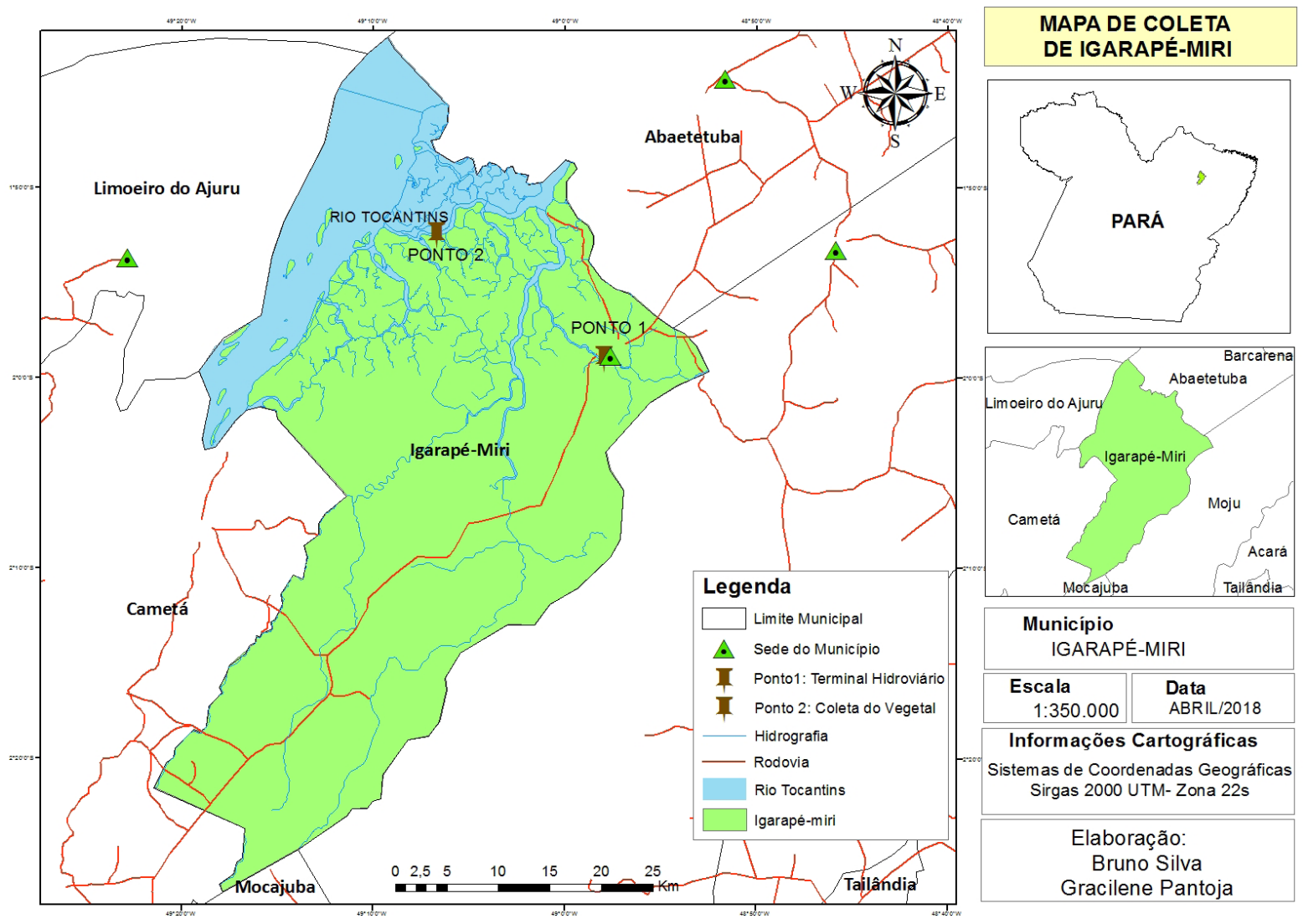

Fonte: Pesquisa de campo, 2018.

Figura 4 ( $A$ e B) - Material testemunho incorporado à coleção botânica do Instituto Federal do Pará - Campus Abaetetuba.

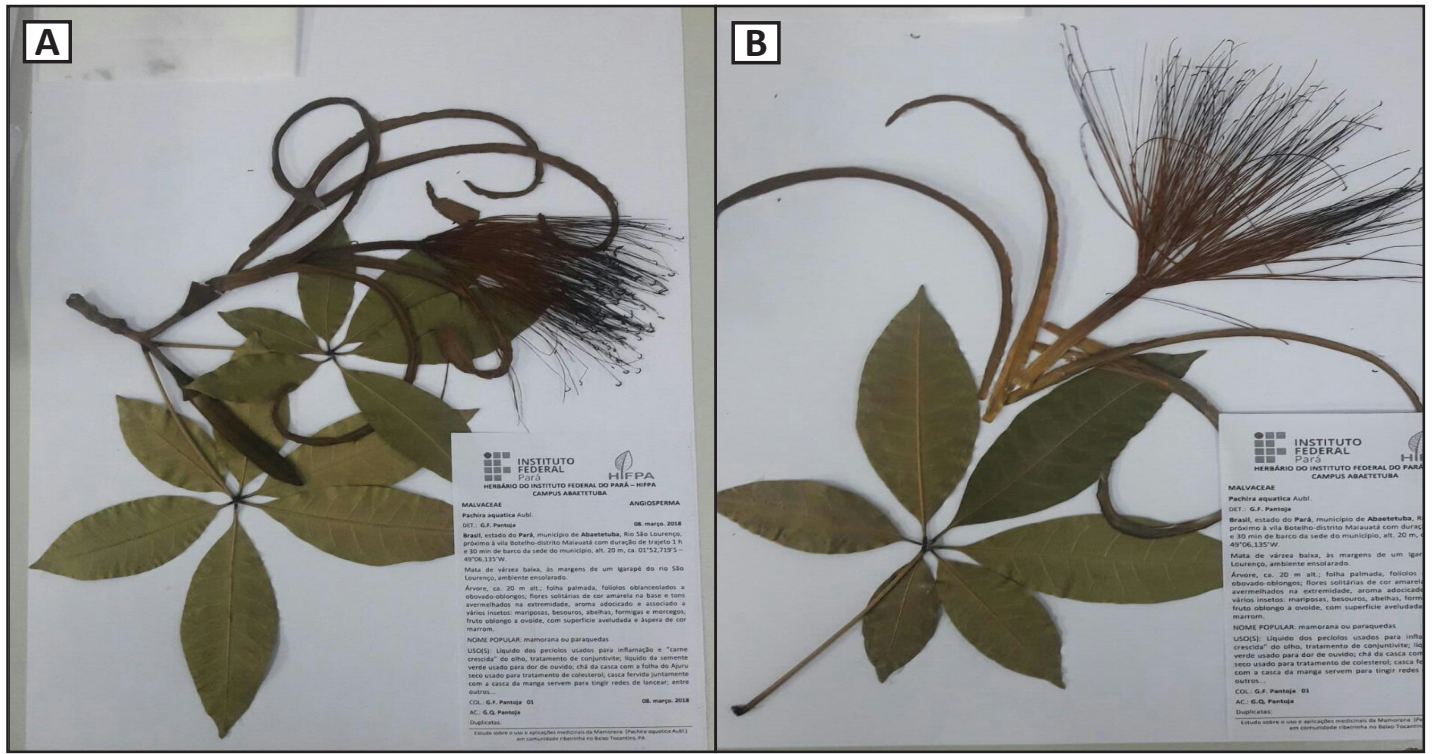

Fonte: Pesquisa de campo, 2018. 


\subsection{Caracterização do público-alvo}

A faixa etária dos onze (11) informantes era de 50 a 88 anos, sendo que a maioria (45\%) tinha entre 60 e 79 anos de idade; 36\%, de 50 a 59 anos; e 18\%, de 80 a 88 anos. Desses, 45\% eram do sexo masculino e $54 \%$ do sexo feminino.

Entre os informantes da pesquisa, 27\% (3) eram oriundos do município de Abaetetuba, PA: sendo dois (2) da localidade Rio Cutininga e um (1) de Guajará de Beja. Os demais 73\% (8) sempre pertenceram, desde seu nascimento, ao município de Igarapé-Miri, PA: sendo (3) da localidade Rio São Lourenço, quatro (4) do Rio Maiauatá (médio e baixo) e um (1) do Rio das Flores.

Em relação ao grau de escolaridade dos informantes, dois (2) eram alfabetizados, porém dois (2) não eram. Seis (6) não haviam concluído o ensino fundamental e apenas um (1) havia concluído o Ensino Médio. Esses dados corroboram os de Pinto (2008) nas comunidades da área rural no município de Igarapé-Miri, PA, inclusive no lócus de pesquisa Rio São Lourenço, em que o maior percentual de entrevistados tinha o ensino fundamental incompleto. Esse fator talvez esteja associado à carência de escolas na comunidade até o ano de 2008, visto que, até então, não havia instituição que atendesse o ensino fundamental maior e, para prosseguir nos estudos, os ribeirinhos tinham de deslocar-se para outras localidades, o que era difícil para muitos.

Entre todos os entrevistados, seis (6) exercem a profissão de lavrador(a)/agricultor(a), sendo essa, inclusive, a de maior predominância; dois (2) são pescadores; dois (2), domésticos; e uma (1) é autônoma. Esses dados confirmam que, na localidade Rio São Lourenço, ocorre o mesmo que no restante do estuário amazônico, cujos habitantes mantêm uma forte relação de dependência com os recursos naturais (SANTOS; COELHO-FERREIRA, 2011).

\subsection{Conhecimentos sobre o vegetal estudado}

Quando indagados sobre o nome popular da Pachira aquatica Aublet, dez (10) conheciam por mamorana e um (1) por paraquedas. De acordo com os entrevistados, o primeiro nome está relacionado à semelhança do fruto com o mamão, já o segundo, às características de resistência da árvore, como justifica uma informante, ao dizer: "É paraquedas, porque ela verga, mas não quebra" (Inform. 7, 50 anos).

De acordo com o dicionário Houaiss da língua portuguesa (HOUAISS; VILLAR, 1999), a palavra "mamorana" é resultado da junção de "mamão" com o termo tupi "rana", que significa "semelhança", o que corrobora a justificativa dos entrevistados. A palavra é também bastante conhecida pela comunidade de pesquisa e presente em diferentes literaturas e sites da internet; por outro lado, não foram encontrados estudos a respeito do termo "paraquedas" como um nome popular associado à Pachira aquatica Aublet.

Quanto à utilização do vegetal, verificou-se que, do total de entrevistados, 63\% (7) fazem ou já fizeram uso desse, sendo que 54\% (6) utilizam para fins medicinais, e $9 \%$ (1), como tingente. Os demais, 37\% (4), embora não o utilizem para nenhuma finalidade, afirmam ter ouvido falar sobre o uso. Perante o exposto, contata-se que a maioria dos entrevistados tem o hábito de utilizar a planta medicinal para fins terapêuticos. Diante disso, concorda-se com estudos realizados por Pinto (2008), ao enfatizar sobre o uso de plantas medicinais para o tratamento de doenças como um elemento ainda presente na cultura da população da área rural do município de IgarapéMiri, PA. 
Por outro lado, embora a comunidade tenha essas preferências de uso da planta, existem estudos que comprovam outras utilidades, como o uso da semente para fins alimentares, conforme destacam Peixoto e Escudeiro (2002) e Silva e Lemos (2002).

Quanto às formas de uso, dos 63\% que utilizam a planta, 27\% (3) desses entrevistados usam-na para dor de ouvido e, ao mesmo tempo, para: I) Controlar o diabetes, II) inflamação nos olhos e conjuntivite; $18 \%$ (2) usam para inflamação nos olhos e, ao mesmo tempo, para: I) "carne crescida" e II) hematoma nos olhos; 9\% (1) usam somente para o tratamento de colesterol e escabiose (conhecida pelos ribeirinhos do lócus de pesquisa como "curuba"); e 9\% (1) usam somente para tingir redes de lancear.

Percebe-se que há várias formas de usos desse vegetal, o que talvez facilite essa manipulação diversificada é a grande variedade de propriedades químicas que ele tem, sendo comprovado em estudos realizados por Cheng et al., (2017), quando estudavam os constituintes anti-inflamatórios de plantas formosas. Muitas espécies foram testadas quanto à atividade inibitória in vitro sobre respostas pró-inflamatórias neutrofílicas, e P. aquática foi encontrado para ser uma espécie ativa.

Quanto ao modo de preparo dos remédios caseiros, partes da árvore utilizada nos preparos caseiros, dosagem e herança de conhecimento sobre a planta, é possível conferir as afirmações dos sujeitos entrevistados em suas narrativas a seguir (ver também quadro-síntese, Quadro 1).

Quadro 1 - Quadro síntese sobre indicações ou usos da planta Pachira aquática Aublet, parte utilizada, modo de preparo e dosagem adotada pela comunidade do Rio São Lourenço, município de Igarapé-Miri, Amazônia

\begin{tabular}{|c|c|c|c|}
\hline Indicações ou usos & $\begin{array}{c}\text { Parte } \\
\text { utilizada }\end{array}$ & Modo de preparo & Dosagem \\
\hline Dor de ouvido & Fruto & $\begin{array}{l}\text { Extrair a mucilagem in natura presente no fruto } \\
\text { verde e colocar no ouvido por } 20 \text { minutos. }\end{array}$ & $1 / 2$ ou 1 colher. \\
\hline \multirow[t]{2}{*}{$\begin{array}{l}\text { Inflamação e } \\
\text { hematoma nos olhos }\end{array}$} & Fruto & $\begin{array}{l}\text { 1) Partir o fruto, extrair a mucilagem in natura } \\
\text { e lavar os olhos. } \\
\text { 2) Cortar o fruto, extrair a mucilagem e colocar } \\
\text { em um recipiente com água por } 1 \text { h. Coar e } \\
\text { lavar os olhos. }\end{array}$ & \\
\hline & Casca & $\begin{array}{c}\text { Cortar a casca e colocar a resina no canto dos } \\
\text { olhos. }\end{array}$ & \\
\hline $\begin{array}{l}\text { "Carne crescida" do } \\
\text { olho e conjuntivite }\end{array}$ & Pecíolo & Extração de mucilagem por maceração. & 1 gota. \\
\hline Controlar o diabetes & Casca & Decocção da casca. & $\begin{array}{l}\text { Não indicação } \\
\text { de dosagem. }\end{array}$ \\
\hline $\begin{array}{l}\text { Tratamento de } \\
\text { colesterol }\end{array}$ & Casca & Infusão da casca no chá da folha do ajuru seco. & $\begin{array}{l}\text { Não indicação } \\
\text { de dosagem. }\end{array}$ \\
\hline Escabiose ("curuba") & Casca & $\begin{array}{l}\text { Limpar a casca, colocar em um recipiente com } \\
\text { água e deixar no Sol até soltar o colorante. }\end{array}$ & $\begin{array}{c}\text { Tomar banho } \\
\text { duas ou três } \\
\text { vezes. }\end{array}$ \\
\hline $\begin{array}{l}\text { Tingir rede de lancear/ } \\
\text { de pesca artesanal }\end{array}$ & Casca & Decocção da casca junto da casca da manga. & \\
\hline
\end{tabular}

Fonte: Pesquisa de campo, 2018.

Para Inflamação e hematoma nos olhos (aprendeu com a mãe oriunda do Rio Maiauatá, Igarapé-Miri, PA): 
A fruta (Figura 5), quando ela está verdinha, ela tem uma goma e ela faz refrescar o baque do olho ou uma inflamação, [...] ela é atorada no meio que é bem molinha, colocado dentro de uma vasilha com água e com poucas horas de tempo (creio que uma hora), aí a minha mãe colocava dentro, colocava um pano e coava aquela água pra ficar bem limpinho pra pessoa usar pra aquela inflamação, porque às vezes era baque, né, ela fazia quase o mesmo efeito que a buta faz [...] A buta é um cipó, vende muito na cidade, ela é cortada colocada na água e ela troca a cor da água, fica amarela, aí coa ela e coloca na inflamação [...] essa inflamação era no olho [...] colocava e lavava com essa água, banhava o olho com aquela água que já tinha saído aquela substância daquela fruta, né. (Informante 1, 53 anos).

Figura 5 - A) fruto verde Pachira aquática Aublet; B) líquido do fruto da Pachira aquática Aublet utilizado para dor de ouvido e inflamação nos olhos

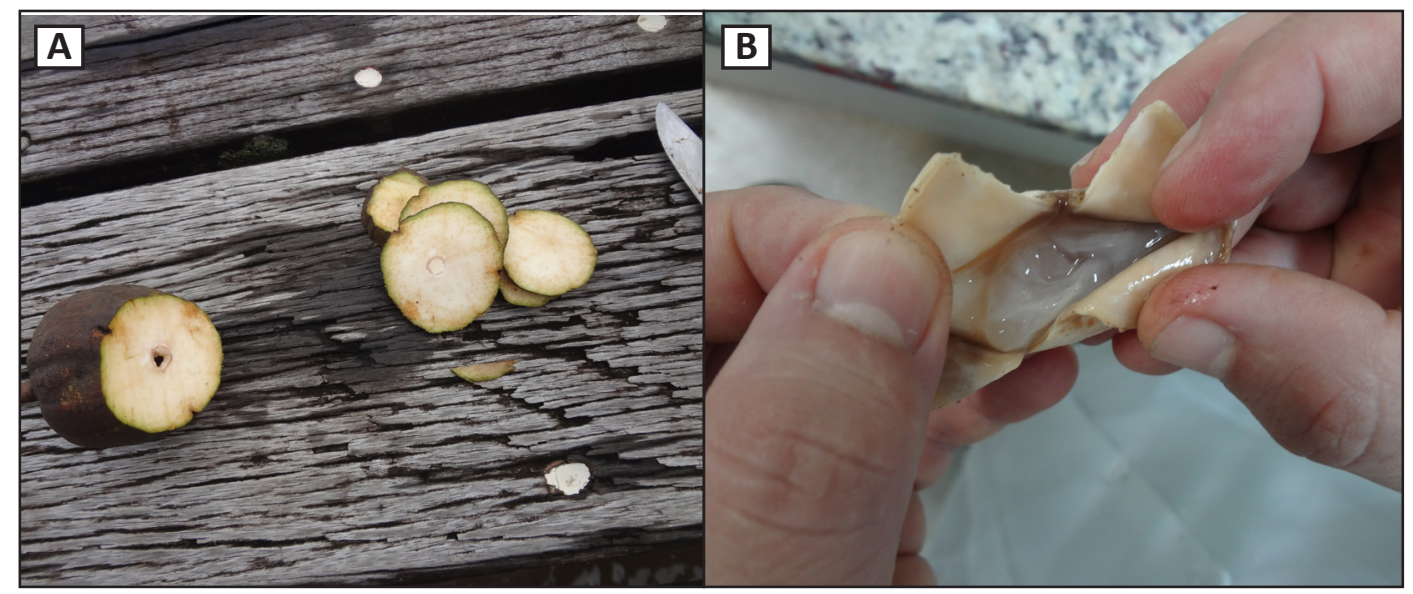

Fonte: Pesquisa de campo, 2018.

Inflamação e "carne crescida" nos olhos (aprendeu com uma "parteira" do Rio Cutininga e amigos do município de Abaetetuba):

(1) A gente parte ela e tira um negócio que tem dentro, branquinho, e coloca no olho, lava o olho quando está inflamado com essa água que tem.

(2) O cabo a gente tira da folha (Figura 6 [A e B]) coloca dentro da água e deixa, depois tira aquilo, aquela gosma que sai do talo e pinga no olho. [...] Quantos minutos? A hora que ficar gosmento assim. (Informante 4, 88 anos).

Figura 6 (A e B) - Extração do líquido dos pecíolos utilizado para inflamação nos olhos

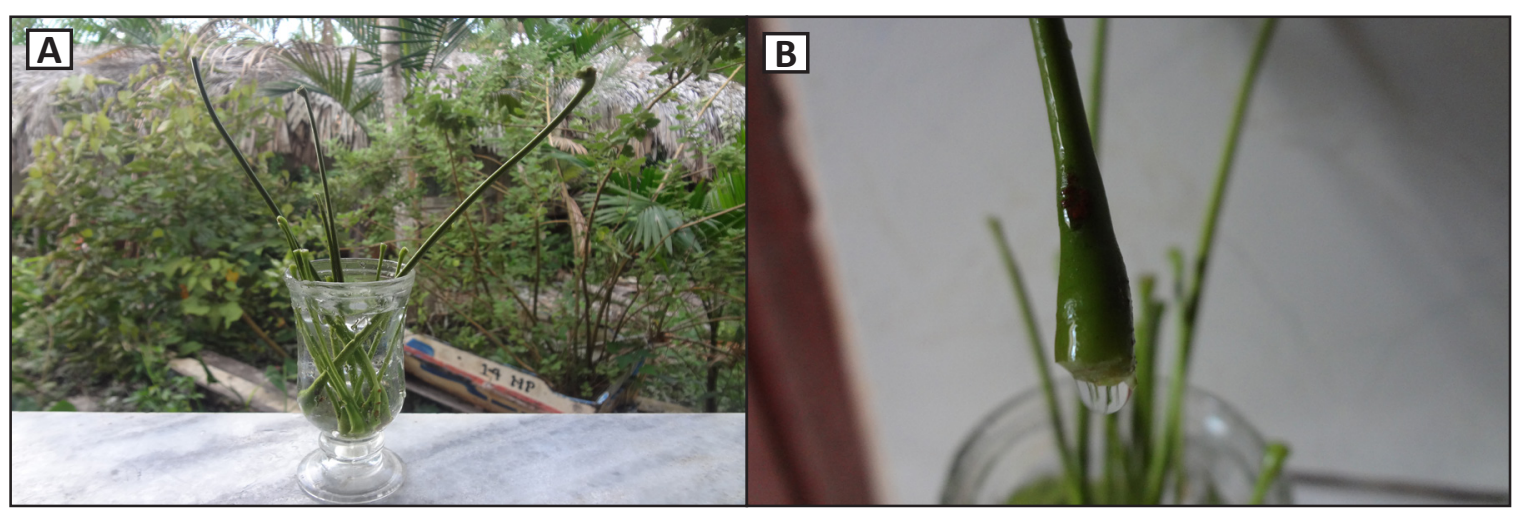

Fonte: Pesquisa de campo, 2018. 
Para dor de ouvido (aprendeu com um amigo da comunidade):

O fruto (Figura 6) é partido quando está verdinho e dentro dele tem uns potinhos, cheio de um líquido branco igual um óleo (é meio deslizante aquele líquido) e tira aquela casquinha mole com cuidado, é uma pelinha fina, ai é só colocar uma vasilha, pode ser uma colher também, às vezes dá uma colher cheia, às vezes dá meia, é conforme o tamanho do potinho, é fria aquela água que dá é alva, alva, alva e deslizante. [...] coloca no ouvido e demora um pouco ali, depois vira e escorre tudinho, deixa ficar molhado, ai desinflama e tira a dor. [...] É uns vinte minutos que fica com a água assim no ouvido. Quando a pessoa vai escorrer, sai morna aquela água, aí vai parando a dor e desinflama. (Informante 5, 67 anos).

Para dor de ouvido, olho inflamado (conjuntivite) (aprendeu com um amigo no município de Acará):

(1) A gente corta, ai apara numa vasilhazinha o oleozinho da fruta verde para poder colocar no ouvido [...] conforme tiver a dor, colocar.

(2) Corta a casca e a resina que sai coloca no canto do olho, já fiz e deu certo. (Informante 10,86 anos)

Para tingir redes de lancear (aprendeu com o avô e o pai do Rio Cutininga):

Meu pai tirava a casca da árvore, cortava tudo em pedacinhos, colocava na panela para ferver junto com a casca da manga, quando baixava do fogo a panela, tirava as cascas e aí metia a rede dentro, fica a água preta, aí o fio branco da rede ficava pretinho. [...] tinha que ficar preta pra lancear, pra durar mais. (Informante 6, 56 anos).

De acordo com as narrativas, percebe-se que existe uma única parte da planta sendo utilizada para finalidades terapêuticas distintas ou que diferentes tipos de partes são indicados para uma única finalidade terapêutica, sendo uma delas associadas a outros vegetais para se ter o efeito desejado. Com isso, constata-se a riqueza do conhecimento da comunidade tradicional pesquisada, sendo evidente não somente pelos usos, mas pelas diferentes formas de manipulação do vegetal. Esses aprendizados provêm da troca de saber com amigos e familiares de suas comunidades de origem. Essa herança de conhecimento associada às vivências dos sujeitos também é evidente nas pesquisas etnobotânicas realizadas na Amazônia por Santos, CoelhoFerreira e Lima (2018) e Pereira e Coelho-Ferreira (2017).

É importante ressaltar que pesquisas realizadas por Fonseca; Ribeiro e Costa (2013) em comunidades na área rural no Baixo Tocantins, PA, têm enfatizado que a obtenção de vegetais pelos moradores na própria comunidade sugere uma correlação entre uso/conhecimento de determinadas plantas medicinais e a disponibilidade delas, o que não é diferente na comunidade de pesquisa, em que 91\% (10) dos entrevistados têm a Pachira aquatica Aublet em suas propriedades e apenas $9 \%$ (1) não a têm, podendo esse quesito estar relacionado ao uso.

Nesse aspecto, pondera-se que, embora a Pachira aquatica Aublet seja bastante utilizada para fins medicinais pelos ribeirinhos do Rio São Lourenço, em estudos realizados por Pinto (2008), sobre plantas medicinais nos anos 2000 e 2008, com 1.397 famílias em 70 comunidades do município de Igarapé-Miri, PA, sendo 53 da área rural (uma delas, lócus desta pesquisa), foram levantadas 236 plantas medicinais utilizadas pelos moradores, porém ressalta-se que, nos resultados desta pesquisa, a Pachira aquatica Aublet não é citada. 


\section{CONCLUSÃO}

Com este estudo, foi possível constatar nove (9) tipos diferentes de indicações e/ou usos da Pachira aquatica Aublet pelos ribeirinhos de São Lourenço, os quais são oriundos de quatro (4) comunidades distintas (Maiauatá, Rio das Flores, Cutininga e Guajará de Beja), tendo uma memória cultural ainda viva em relação à planta medicinal, mas de certa forma invisibilizada, visto que no momento em que os sujeitos mais longevos expressavam sobre o conhecimento que possuem, ao mesmo tempo reportavam para o fato de perceberem essa prática, muitas vezes, não ser valorizada, carecendo de estudos etnobotânicos mais amplos que visem documentar o vasto conhecimento que ainda possuem, permitindo o diálogo entre as diversas áreas de conhecimento para serem também discutidos nas escolas do campo com as gerações atuais, de forma a manter essa cultura e a preservar a memória e identidade local, bem como facilitar a aprendizagem por meio de um elemento cultural presente na comunidade.

\section{APOIO}

Pró-Reitoria de Pesquisa e Pós-Graduação - Propesp/UFPA.

\section{REFERÊNCIAS}

ABÍLIO, G. M. F. Plantas Medicinais. In: MEDEIROS, G. M.; ARAÚJO, L. F. (Org.). Cadernos de Licenciatura em Ciências Agrárias/Universidade Aberta do Brasil/Universidade Federal da Paraíba; Centro de Ciências Humanas Sociais e Agrárias. Bananeiras: Editora Universitária/UFPB, 2011. v. 6. Caderno Especial 03.

ALMEIDA, M. Z. Plantas Medicinais. 3. ed. Salvador: EDUFBA, 2011.

BÔAS, L. M. S. V. Saber popular e o saber científico: um diálogo intercultural possível no cuidado ribeirinho. In: CONGRESSO IBERO-AMERICANO DE INVESTIGAÇÃO QUALITATIVA, 5., 12-14 de julho de 2016. Porto, Portugal. Atas [...]. Porto: Ciaiq, 2016. v. 2.

BRAGA, C. M. Histórico da utilização de plantas medicinais. 2011. 24 f. Monografia (Licenciatura em Ciências Biológicas) - Consórcio Setentrional de Educação a Distância, Universidade de Brasília, Brasília, DF, 2011.

BRASIL. Ministério da Saúde. Resolução n. 466, de 12 de dezembro de 2012. Disponível em: http:// andromeda.ensp.fiocruz.br/etica/sites/default/files/documentos/Res\%20466_2012.pdf. Acesso em: 3 maio 2018.

BRASIL. Decreto n. 6.040, de 7 de fevereiro de 2007. Institui a Política Nacional de Desenvolvimento Sustentável dos Povos e Comunidades Tradicionais. Disponível em: http://www.planalto.gov.br/ccivil_03/_ ato2007-2010/2007/decreto/d6040.htm. Acesso em: 30 set. 2018.

CHENG, L. Y.; CHEN, L. C; LIAO, H. R.; WANG, S. W.; KUO, Y. H.; CHUNG, M. I.; CHEN, J. J. Naphthofuranone derivatives and other constituents from Pachira aquatica with inhibitory activity on superoxide anion generation by neutrophils. Fitoterapia, v. 117, p. 16-21, 2017.

COUTO-WALTRICH, C; BOFF, P.; BOFF, M. I. C. Etnoconhecimento associado às amoreiras-brancas (Rubus spp.) ocorrentes na Floresta Ombrófila Mista, Santa Catarina, Brasil. Revista de la Facultad de Agronomía, La Plata, v. 116, n. 1, p. 13-18, 2017.

ELISABETSKY, E. Etnofarmacologia. Ciência e Cultura, v. 55, n. 3, p. 35-36, 2003. 
FONSECA, D. J. S.; RIBEIRO, I. C.; COSTA, J. M. Plantas medicinais usadas pelos moradores da Vila de Beja. In: CONGRESSO NACIONAL DE BOTÂNICA, 64., 10-15 novembro de 2013, Belo Horizonte. Anais [...]. Belo Horizonte: UFMG, 2013.

HOUAISS, A.; VILLAR, M. DE S. Dicionário Houaiss da língua portuguesa. Rio de Janeiro: Instituto Antônio Houaiss de Lexicografia; Banco de Dados da Língua Portuguesa S/C Ltda; Objetiva Ltda., 1999.

INFANTE-MATA, D.; MORENO-CASASOLA, P.; MADERO-VEGA, C. ¿Pachira aquatica, un indicador del límite del manglar? Revista Mexicana de Biodiversidad, v. 85, n. 1, p. 143-60, 2014.

JORGE, S. S. A. Plantas medicinais: coletânea de saberes. Viçosa: Esuv, 2009.

LORENZI, H. Árvores brasileiras: manual de identificação e cultivo de plantas arbóreas nativas do Brasil. São Paulo: Nova Odessa/Plantarum Ltda., 1992.

PANTOJA, G. F.; PINHEIRO, E. S.; SANTOS, L. R.; SILVA, L. M. S. Escola do campo e o universo de famílias rurais. In: OLIVEIRA, M. R. D.; SILVA, L. M. S.; RAMOS, G. L. A. (Org.). Práticas de pesquisa e realidade camponesa. Rio de Janeiro: Autografia, 2018. p. 176-207.

PEIXOTO, A. L.; ESCUDEIRO, A. Pachira aquatica (Bombacaceae) na obra "História dos Animais e Árvores do Maranhão" de Frei Cristóvão de Lisboa. Rodriguésia, v. 53, n. 82, p. 123-30, 2002.

PEREIRA, M. G. S.; COELHO-FERREIRA, M. Uso e diversidade de plantas medicinais em uma comunidade quilombola na Amazônia Oriental, Abaetetuba, Pará. Biota Amazônia, p. 57-68, 2017.

PESCE, C. Oleaginosas da Amazônia. 2. ed. Belém: Museu Paraense Emílio Goeld, 2009.

PINTO, L. DO N. Plantas medicinais utilizadas em comunidades do município de Igarapé-Miri, ParáEtnofarmácia no município de Igarapé-Miri-PA. Belém: PPGCF/UFPA, 2008.

SANTOS, J. J. F.; COELHO-FERREIRA, M.; LIMA, P. G. C. Etnobotânica de plantas medicinais em mercados públicos da Região Metropolitana de Belém do Pará, Brasil. Biota Amazônia, v.8, n. 1 p. 1-9, 2018.

SANTOS, R. S.; COELHO-FERREIRA, M. Miriti artifacts (Mauritia flexuosa L. f.) in Abaetetuba, Pará State, Brazil: from production to marketing. Boletim do Museu Paraense Emílio Goeldi. Ciências Humanas, v. 6, p. 559-71, out. 2011.

SANTOS-SILVA, J. P. G.; OLIVEIRA, P. C. Etnobotânica de plantas medicinais na comunidade de várzea Igarapé do Costa, Santarém-Pará, Brasil. Revista del Doctorado Interinstitucional en Ciencias Ambientales, v. 6. p. 136-51, 2016.

SILVA, Amanda Stefanie Sérgio da. Etnoconhecimento sobre plantas medicinais e inter-relações com o meio ambiente na comunidade do Catu, Canguaretama (RN, Brasil). 2018. 81f. Dissertação (Mestrado em Desenvolvimento e Meio Ambiente) - Centro de Biociências, Universidade Federal do Rio Grande do Norte, Natal, 2018. Disponível em: https://repositorio.ufrn.br/jspui/handle/123456789/25517

SILVA, D. B.; LEMOS, B. S. Plantas da área verde da Super Quadra Norte 416 - Brasília. Brasília: Embrapa, 2002.

SILVA, S. M. G.; NASCIMENTO, K. G. S.; FRAXE, T. J. P.; BRAGA, P. I. S. A "saúde" nas comunidades focais do projeto Piatam: o etnoconhecimento e as plantas medicinais. In: FRAXE, T. J. P.; PEREIRA, H. S.; WITKOSKI, A. C. (Org.). Comunidades ribeirinhas amazônicas: modos de vida e uso dos recursos naturais. Manaus, AM, Brasil: Reggo, Edições, 2011. 
SEBEM, E.; MONGUILHOTT, M. Curso de Cartografia Básica, GPS e ArcGIS. Santa Maria: Colégio Politécnico da UFSM/RS, 2010. $228 p$

\section{Sobre os autores:}

Gracilene Ferreira Pantoja: Mestranda do Programa de Pós-Graduação em Cidades, Territórios e Identidades (PPGCITI) na Universidade Federal do Pará (UFPA), Campus Universitário de Abaetetuba, com vínculo à linha de pesquisa: Políticas Públicas, Movimentos Sociais e Territórios. Graduada em Educação do Campo, com ênfase em Ciências Naturais - Licenciatura -, pela UFPA, Campus Universitário de Abaetetuba. Integrante do Grupo de Estudos sobre a Biodiversidade e Sustentabilidade na Amazônia Tocantina e do Grupo de Pesquisa Desenvolvimento Rural e Inovação Sociotécnica (Dris). Experiência com temas relacionados à Educação do Campo; Etnobotânica; Ensino de Ciências Naturais; Agricultura Familiar; Cartografia Social; Territorialidade; Políticas Públicas socioambientais. E-mail: gracilenepantoja.gp@gmail.com, Orcid: http://orcid.org/0000-0002-1946-8768

Yvens Ely Martins Cordeiro: Doutorado em Ciências Agrárias, área de concentração em Agroecossistemas da Amazônia, pelo Convênio Ufra/Embrapa. Mestrado em Ciências Agrárias, área de concentração em Biologia Vegetal Tropical pela Universidade Federal Rural da Amazônia. Graduação em Ciências Biológicas pela Universidade Federal do Pará (UFPA). Experiência na área de Meio Ambiente e Educação no Campo. Professor adjunto II, da UFPA, atuando principalmente em pesquisa, ensino e extensão na área da Educação no Campo, especificamente com temas relacionados às práticas agroecológicas na agricultura familiar. Experiência na área da territorialidade, espaços escolares rurais, etnoconhecimento, educação ambiental e tecnologias para o campo. E-mail: yemcordeiro@ufpa.br, Orcid: http://orcid.org/0000-0003-0596-002X

Sebastião Gomes Silva: Doutorando e mestre em Química Orgânica pela Universidade Federal do Pará (UFPA). Especialista em Aplicabilidade de Novas Tecnologias como Ferramentas Pedagógicas para o Ensino de Ciências (Química e Física) e graduado em Ciências Naturais/Química pela UFPA. Professor efetivo, classe II, da Rede Estadual de Ensino do estado do Pará (Seduc-Pará). Atua na área de Química, com ênfase em Química de Produtos Naturais e Informática Educativa, principalmente nos seguintes temas: extração de óleos essenciais por hidrodestilação, arraste a vapor, destilação e extração simultânea, análise por cromatografia gasosa/espectrômetro de massa, além de testes biológicos e busca por aplicações dos óleos essenciais nas indústrias. E-mail: profsebastiaogs@gmail.com, Orcid: http://orcid.org/0000-0002-7348-4961

Ronaldo Lopes de Sousa: Doutorado em Biologia de Agentes Infecciosos e Parasitários pela Universidade Federal do Pará (UFPA). Professor adjunto I da UFPA, no Curso de Licenciatura em Educação do Campo - Ciências Naturais. Experiência na área de Animal, com ênfase em Ciências Biológicas, Etnobotânica, Virologia e Biologia Molecular. E-mail: ronaldosousa@ufpa.br, Orcid: http://orcid.org/0000-0002-5440-2959 